\title{
Knowledge About Indirect Composite Among Dental Students-A Questionnaire Survey
}

\author{
S.Padmaja ${ }^{1}$, Subhabrata Maiti ${ }^{2}$ and Keerthi Sasanka ${ }^{3}$ \\ ${ }^{1}$ Saveetha Dental College and Hospitals, Saveetha Institute of Medical and \\ Technical Sciences, Saveetha University, Chennai-77,Tamilnadu,India. \\ ${ }^{2}$ Senior Lecturer, Department of Prosthodontics, Saveetha Dental college and \\ Hospitals, Saveetha Institute of Medical and Technical Sciences, Saveetha \\ University, Chennai-77,Tamilnadu,India. \\ ${ }^{3}$ Senior Lecturer, Department of Prosthodontics, Saveetha Dental college and Hospitals, \\ Saveetha Institute of Medical and Technical Sciences, Saveetha University, \\ Chennai-77,Tamilnadu, India
}

\section{ABSTRACT}

Composites are playing an important role in aesthetic dentistry and it is essential to have in depth knowledge of them. Indirect composite is now being rapidly developed. Indirect composite helps us to overcome the drawbacks of direct composite like polymerisation stresses. Indirect composite have better bonding and are having unlimited working time. Nearly half of the population were aware of the characteristics of indirect composite. Nearly half of the population were aware of the composite blanks and use of them in denture characterisation. Most of them were aware of modeling liquid also which helps in avoiding stickiness of composite and helps in color maintenance. Nearly half of the population were not aware of the use of indirect composite to repair or even characterise the ceramics. Indirect composite have better physical and mechanical properties which makes them more stronger than direct composites.Nearly $44 \%$ of our population were only aware of the strength while most of them were not sure about it.Still we need to make most of them aware of the material so that it can help in better efficacy and better clinical usage of them.

KEY WORDS: INDIRECT COMPOSITE, CERAMICS REPAIR, BONDING METHODS, CURING PERIOD, STRENGTH, POLYMERISATION STRESS.

\section{INTRODUCTION}

Aesthetic dentistry is evolving rapidly now. Composites are playing an important role in aesthetic potential during restoration. They provide a stable and pleasant result. With simple layering technique it is possible to

\section{ARTICLE INFORMATION}

*Corresponding Author: subhabratamaiti.sdc@saveetha.com Received 29th July 2020 Accepted after revision 19th Sep 2020 Print ISSN: 0974-6455 Online ISSN: 2321-4007 CODEN: BBRCBA

Thomson Reuters ISI Web of Science Clarivate Analytics USA and Crossref Indexed Journal

$$
\begin{aligned}
& \text { Clarivate } \\
& \text { Analytics }
\end{aligned}
$$

NAAS Journal Score 2020 (4.31) SJIF: 2020 (7.728)

A Society of Science and Nature Publication,

Bhopal India 2020. All rights reserved.

Online Contents Available at: http//www.bbrc.in/

Doi: http://dx.doi.org/10.21786/bbrc/13.8/175 see good results.Composites also serve as alternatives to other restorative materials especially in the aspect of aesthetics as they are available in different shades to resemble the teeth in a natural manner. Composite resin are aesthetic alternatives for amalgam restorations. They are also being used in posterior teeth now. There are two composites that are direct and indirect composite (Azeem and Sureshbabu, 2018). The use of direct composite has been limited in posterior teeth due to polymerization stresses(Mandikos et al., 2001) . The composite material is condensed in increments into cavity and light cured for $40 \mathrm{sec}$ for each surface(Fuhrer, 1997). More recently the use of indirect composite is having a different method of processing. 
The first method includes curing the chamber without oxygen, second includes curing at a slow rate, third method involves introducing heat and light simultaneously into the chamber. In indirect composite the polymerisation level is higher therefore it is superior to direct composite (Bortolotto et al., 2013). They are cured for longer times with high level and depth of cures when compared to direct composites. They are cured outside the mouth and capable of delivering high levels and intensities of energy(Reinhardt, Boyer and Stephens, 1994; Suzuki et al., 2002). Composites are generally preferred over other restorative materials due to many of their properties such as better bonding , used in conservative preparations, offer virtually unlimited working time(Alavi and Kianimanesh, 2002). Indirect composites are also used to fill the teeth cavities and fill gaps between the teeth. They can also reshape the teeth. They can also prepare veneers and adhesive bridges(Leinfelder, 2005).

Restoration done in the way of indirect technique can optimise the marginal integrity. They also have better marginal adaptation which can decrease the incidence of secondary caries(Soares et al., 2005; Angerame et al., 2012). Due to their ability of providing excellent marginal integrity there is a substantial increase in wear resistance (Bartlett and Sundaram, 2006; Rocca et al., 2012). Indirect composite have improved physical properties and have a wide variety of tooth coloured restorative materials with high strength(Souza et al., 2010). Indirect composite wear out soon when compared to amalgam and other restorative materials and they last for a period of 5 years which is a less duration when compared to lifespan of amalgam.This study is of utmost importance now as we progress and advance in prosthetic dentistry. It is important to study about their methods of bonding, their advantages and disadvantages, along with their lifespan and their uses in prosthetic dentistry.

Previously our department has published extensive research on various aspects of prosthetic dentistry ((Ashok et al., 2014; Venugopalan et al., 2014; Ashok and Suvitha, 2016; Ganapathy et al., 2016; Selvan and Ganapathy, 2016; Subasree and Murthykumar, 2016; Vijayalakshmi and Ganapathy, 2016; Ajay et al., 2017; Ganapathy, Kannan and Venugopalan, 2017; Jyothi et al., 2017; Ranganathan, Ganapathy and Jain, 2017; Ariga et al., 2018; Basha, Ganapathy and Venugopalan, 2018; Kannan and Venugopalan, 2018; Duraisamy et al., 2019) . This vast research experience has inspired us to research about the knowledge of indirect composite. Aim of this study helps us to have a better understanding regarding the properties and uses of indirect composite.

\section{MATERIAL AND METHODS}

This study was conducted to dentists and dental students . Sample size was around 70 using the G power software. Questionnaire was prepared and disseminated using the google forms online response collection software. The questionnaire was validated by 5 prosthodontist lecturers. Simple random sampling method was used. The independent variable was gender while the dependent variable was knowledge in indirect composite.SPSS statistical software was used for data analysis. The statistical test used was the chi-square test.

\section{RESULTS AND DISCUSSION}

Responses were collected and analysed. From figure I we can observe that $34.29 \%$ were aware that composite is being used to repair ceramics or even characterise them. From figure II we can see that nearly half of the population $48.57 \%$ were aware of composite blanks while the remaining were oblivious to the fact.From figure III , we can see that nearly $42.86 \%$ were aware of the methods of bonding of composite to ceramic. From figure IV we can see that nearly $61.43 \%$ that is more than half of the population were aware of indirect composite being used in denture characterization. From figure V we can observe that more than half of the population that is $57.14 \%$ was aware of the use of modeling liquid. From figure VI we can see that $44.29 \%$ were aware of the fact that indirect composite exert more strength when compared to direct composite. From figure VII it is shown that $70 \%$ of the population have known the fact that polyvinyl siloxane is used as die material for chair side work. From figure VIIIwe can see that 51.43\% which is nearly half of the population were aware of the proper polishing protocol for indirect composites.

Figure 1: awareness of composite being used to repair ceramics or even characterize them. Nearly $34.29 \%$ of the population is aware of it while $54.29 \%$ are not aware. $11.43 \%$ were not sure about it.

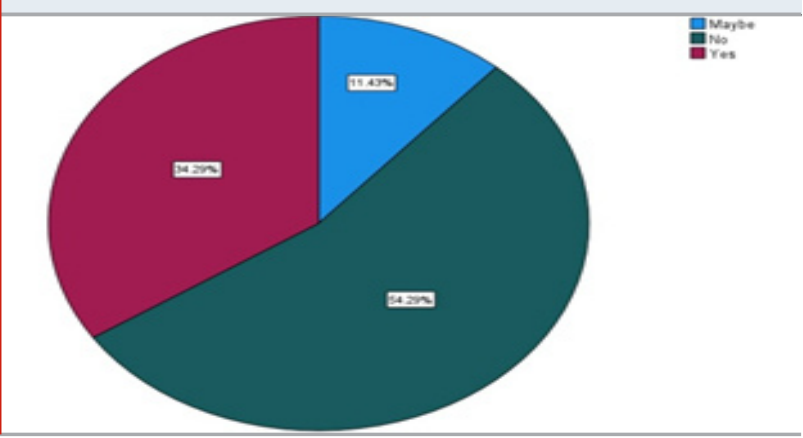

Figure 2: awareness of composite blanks. This chart shows that nearly $48.57 \%$ of the population were aware of it while nearly $21.43 \%$ were not aware and $30 \%$ were not sure.

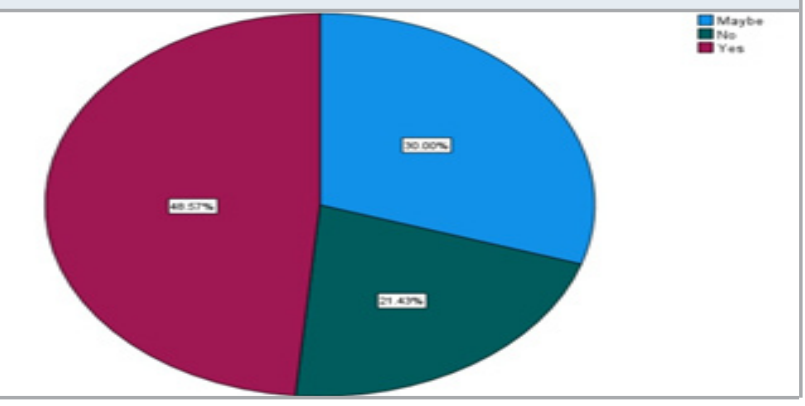


Figure 3: awareness of method of bonding of composite to ceramic. This chart shows that nearly $42.86 \%$ of the population was aware of it while $27.14 \%$ were not aware of it and 30\% were not sure about it.

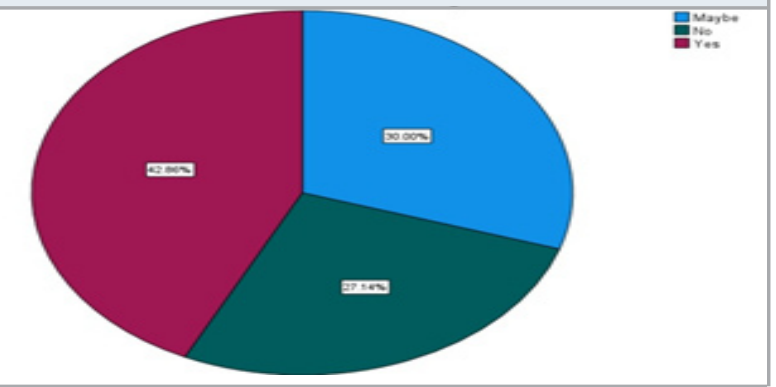

Figure 4: awareness of indirect composite used in denture characterization. This chart shows that nearly $61.43 \%$ of the population were aware of it while $20 \%$ were not aware of it and $18.57 \%$ were not confident about the use of indirect composite for denture characterisation.

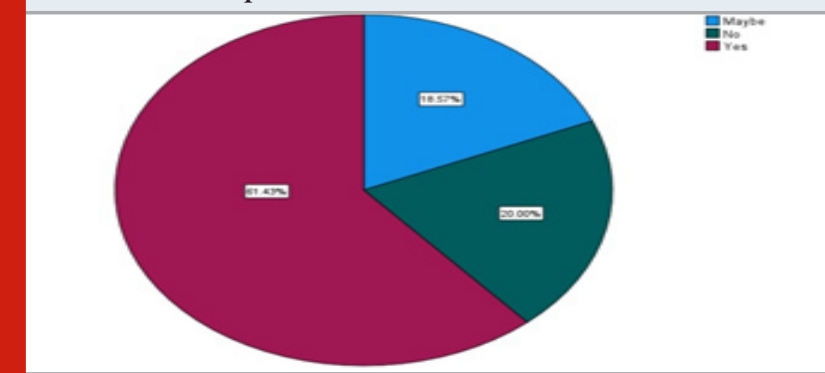

Figure 5: awareness of modeling liquid. This chart shows that nearly $57.14 \%$ were aware which is more than half of the population while $20 \%$ were not aware of it and $22.86 \%$ were not sure about modeling liquid in indirect composite.

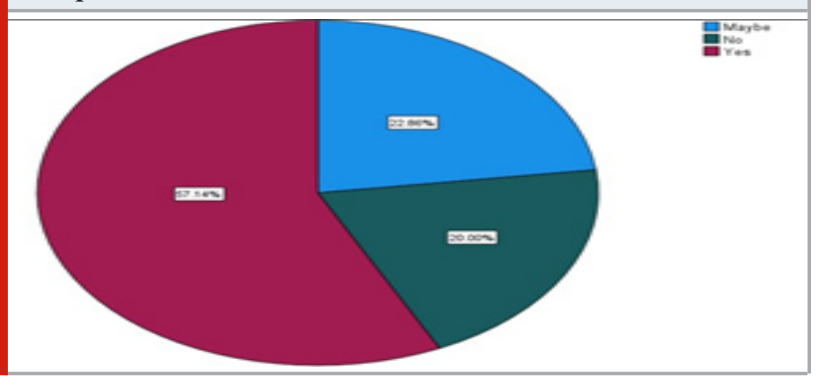

As we make progress in the field of prosthetic dentistry it is important to have in-depth knowledge regarding the restorative material used. Indirect composite is paving their way in prosthetic dentistry which makes it necessary to know about them. Some studies show that indirect composite have high marginal integrity which makes them less susceptible to secondary caries. But some studies contra indicate the results by stating that the marginal gap of direct composites was less when compared to indirect composite in an in vitro study (Zarrati and Mahboub, 2010). Pearson correlation analysis was conducted.Table I shows the values of Chi square and $\mathrm{P}$ values.From figure IX, we can see there is no significant correlation between gender and awareness of indirect composite used to repair ceramics or even characterize them. From figure X, we can see there is no significant relation between gender and awareness of composite blanks. From figure XI, we can see there is no significant relation between gender and awareness of method of bonding of composite to ceramic. From figure XII , we can see there is a significant relation between gender and awareness of indirect composite in denture characterisation.

Figure 6: awareness of indirect composite has more strength than direct composite. This chart shows nearly $44.29 \%$ were aware while $10 \%$ were not aware and $45.71 \%$ were not sure about the strength level of indirect composite.

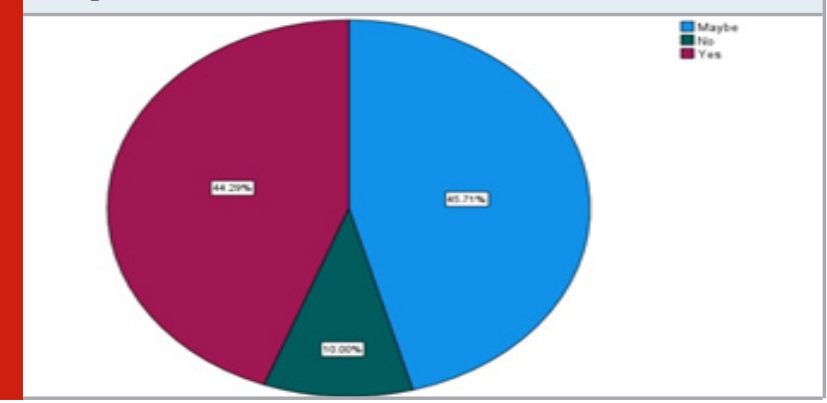

Figure 7: awareness of polyvinyl siloxane as die material in chair side work. Nearly $70 \%$ were aware while $14.29 \%$ were not aware of it and $15.71 \%$ were not confident about it.

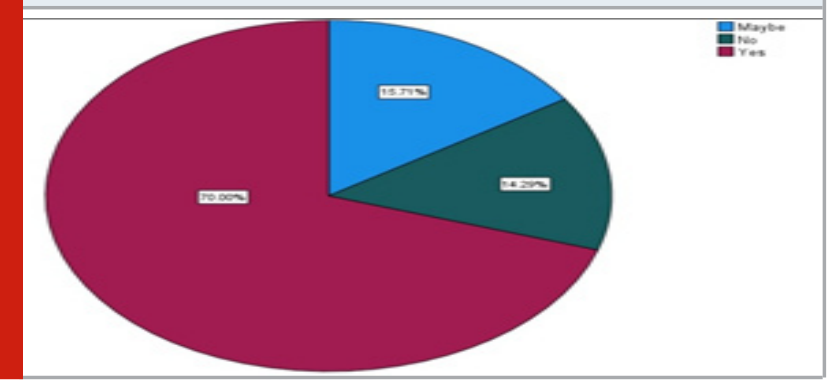

Figure 8: awareness of proper polishing protocol. Nearly $51.43 \%$ were aware which is nearly half of the population while $22.86 \%$ were not aware of it and $25.71 \%$ were not confident about it.

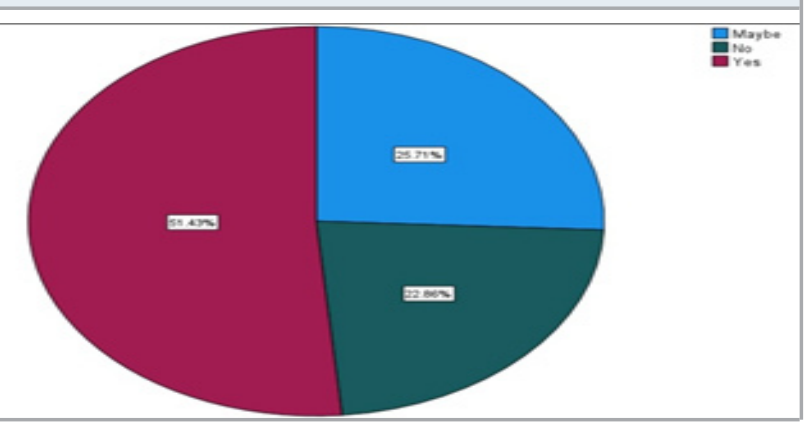


Table 1. This table shows the Chi square and $\mathrm{P}$ values obtained

\begin{tabular}{|c|c|c|c|c|c|}
\hline questions & options & $\begin{array}{l}\text { Response } \\
\text { by female }\end{array}$ & $\begin{array}{l}\text { Response } \\
\text { by male }\end{array}$ & $\begin{array}{c}\text { Chi } \\
\text { square }\end{array}$ & $\mathrm{P}$ value \\
\hline \multirow[t]{3}{*}{ Repair ceramics } & Yes & 12 & 12 & 0.8633 & 0.64 \\
\hline & No & 16 & 22 & & \\
\hline & Maybe & 3 & 5 & & \\
\hline \multirow[t]{3}{*}{ Composite blanks } & Yes & 18 & 16 & 3.2572 & 0.1962 \\
\hline & No & 5 & 10 & & \\
\hline & Maybe & 8 & 13 & & \\
\hline \multirow[t]{3}{*}{ Methods of bonding } & Yes & 11 & 19 & 1.5669 & 0.456 \\
\hline & No & 10 & 9 & & \\
\hline & Maybe & 10 & 11 & & \\
\hline \multirow[t]{3}{*}{ Denture characterisation } & Yes & 15 & 28 & 6.4232 & 0.040 \\
\hline & No & 9 & 5 & & \\
\hline & Maybe & 7 & 6 & & \\
\hline \multirow[t]{3}{*}{ Modeling liquid } & Yes & 18 & 22 & 3.0605 & 0.216 \\
\hline & No & 4 & 10 & & \\
\hline & Maybe & 9 & 7 & & \\
\hline \multirow{3}{*}{$\begin{array}{l}\text { Strength of indirect } \\
\text { composite }\end{array}$} & Yes & 14 & 17 & 1.166 & 0.558 \\
\hline & No & 4 & 3 & & \\
\hline & Maybe & 13 & 19 & & \\
\hline \multirow[t]{3}{*}{ Die material } & Yes & 22 & 27 & 0.4812 & 0.786 \\
\hline & No & 5 & 5 & & \\
\hline & Maybe & 4 & 7 & & \\
\hline \multirow[t]{3}{*}{ Polishing protocol } & Yes & 18 & 18 & 1.6041 & 0.448 \\
\hline & No & 6 & 10 & & \\
\hline & Maybe & 7 & 11 & & \\
\hline
\end{tabular}

Figure 9: This bar graph shows the association between the gender and the people who are aware of composite being used to repair ceramics or even characterize them. The $\mathrm{X}$ axis shows the gender while the $\mathrm{Y}$ axis shows the responses. The green bar shows the negative responses while the red bar shows the positive responses and blue bar shows people who are not sure about indirect composite being used to repair ceramics. The chi square value is 0.8633 and the $P$ value is $0.64(>0.05)$. The $P$ value is not significant. There is no significant relationship between gender and the people who are aware of composite being used to repair or characterise ceramics.

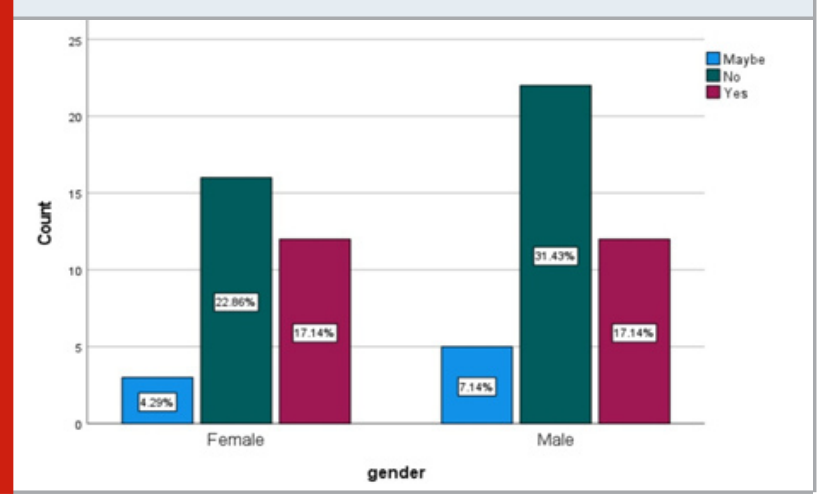

Figure 10 : This bar graph shows the correlation between gender and people aware of composite blanks. The $\mathrm{X}$ axis shows the gender while the $\mathrm{Y}$ axis shows the responses. The green bar shows the negative responses, red bar shows the positive responses and blue bar shows the people who are not sure about the composite blanks. Chi square value is 3.2572 and the $P$ value is $0.1962(>0.05)$. The $P$ value is not significant . There is no significant relationship between gender and people with awareness of composite blanks.

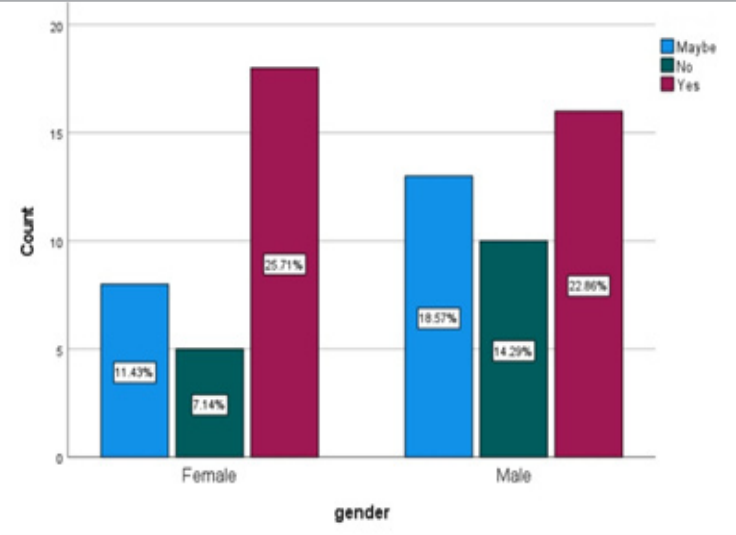


Figure 11: This bar shows the correlation between gender and people who are aware of the methods of bonding for composite to ceramic. The $\mathrm{X}$ axis shows gender while $\mathrm{Y}$ axis shows the responses.The green bar shows the negative responses and the red bar shows the positive responses. The blue bar shows that people are not sure about the methods of bonding for composite to ceramic. The chi square value is 1.5669 and $P$ value is $0.45683(>0.05)$. The $P$ value is not significant so there is no significant relationship seen.

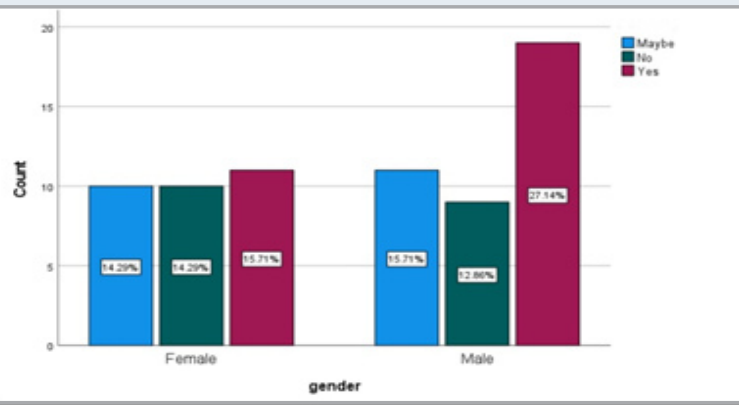

Figure 12: This bar shows the correlation between the gender and people who are aware of the fact that indirect composites are also used for denture characterization. The $\mathrm{X}$ axis shows the gender while the $\mathrm{Y}$ axis shows the responses. The green bar shows the negative responses and red bar for positive responses. Blue bar shows that people are not sure about the fact that indirect composite are used in denture characterisation. The chi square value is $\mathbf{6 . 4 2 3 2}$ and $P$ value is $0.040(<0.05)$. The $P$ value is significant and a significant relationship is seen.

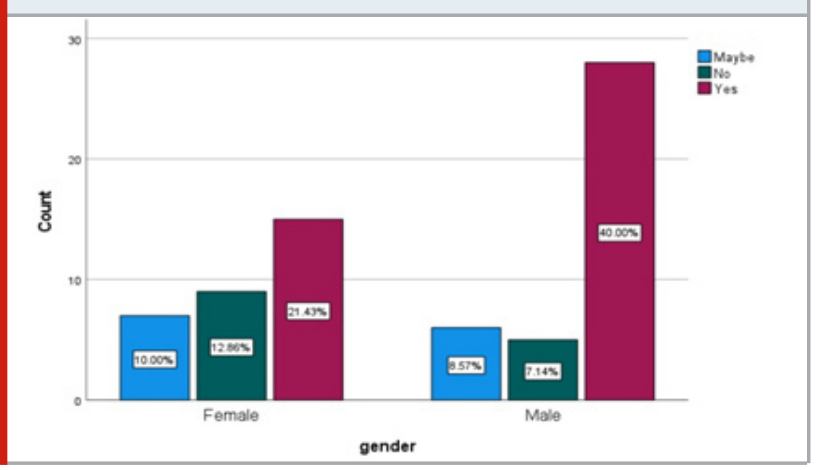

From figure XIII, we can see there is no significant relation between gender and awareness of modeling liquid. From figure XIV, we can see that there is no significant relation between gender and awareness of indirect composite having more strength than direct composite. Form figure XV, we can see that there is no significant relation between gender and awareness of polyvinyl siloxane as die material for chair side work. From figure XVI, we can see that there is no significant relation between gender and awareness of proper polishing protocol. This study also showed that indirect composite depicted no change in marginal gap even after cementation and thermo cycling. In some previous studies $43 \%$ of dental practitioners use indirect composite for posterior teeth while 32\% for anterior teeth and $2 \%$ for repair procedures. Modeling liquids are generally used for color stability of the resin composite which in our survey nearly $52.9 \%$ that is more than half of the population were not aware.

Figure 13: This bar graph shows the correlation between the gender and the awareness of modeling liquid being used. The $\mathrm{x}$ axis shows the gender while the $\mathrm{Y}$ axis shows the responses. The green bar shows the negative responses and red for positive responses while the blue bar shows that people are not sure of modeling liquid. The chi square value is 3.0605 and $P$ value is $0.216(>0.05)$. The $P$ value is not significant and no significant relationship is observed.

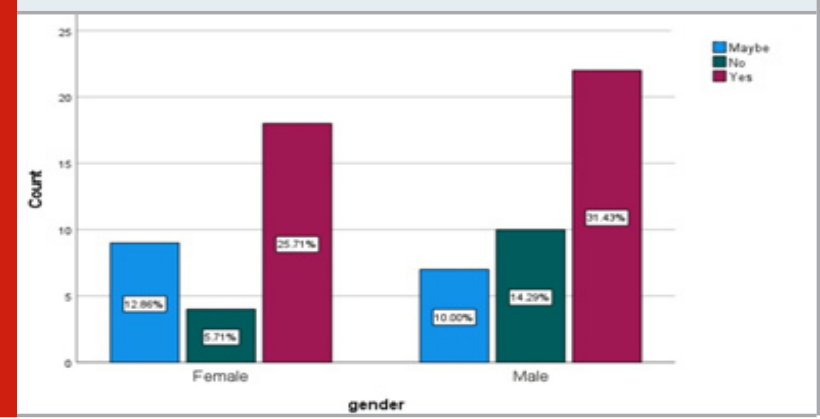

Figure 14: This bar graph shows the correlation between gender and people aware of the fact that indirect composite has more strength than direct composite. The $\mathrm{X}$ axis shows the gender and the $\mathrm{Y}$ axis shows the responses. The green bar shows the negative responses while the red bar shows the positive responses and the blue bar shows people who are not sure about the strength of indirect composite. The chi square value is 1.166 and $P$ value is $0.558(>0.05)$. The $P$ value is not significant and no significant relationship is seen.

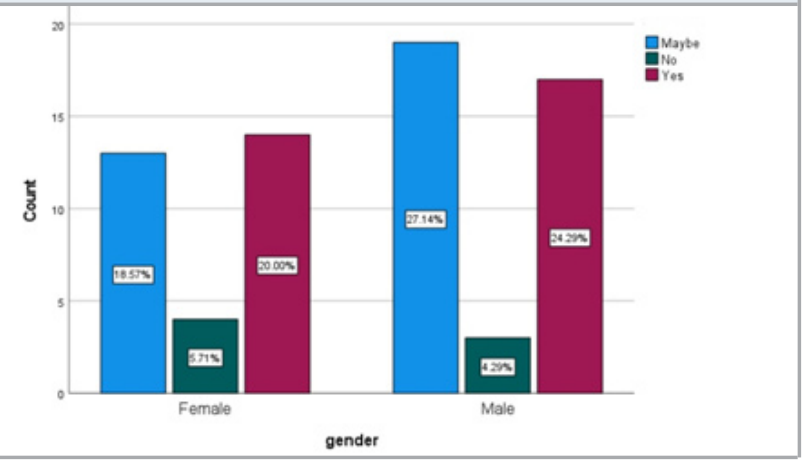

Most of the composites are sticky reducing their ease of handling which is why modeling liquid is being used in indirect composite (ALShetili and Al-Omari, 2016; Sedrez-Porto, Münchow and Brondani, 2016; Araujo et al., 2018; Kutuk et al., 2020). Indirect composites are said to be more hard which is contraindicated in certain studies where direct composite exhibit high flexural strength and hardness on a comparative scale (Borba, Della Bona and Cecchetti, 2009). Despite the characteristics in direct and indirect composites we can 
see that even though both are following the method of incremental build up it is seen that polymerisation shrinkage is less in indirect composite which makes a bit more suitable for application in clinical dentistry(Nandini, 2010; Ozakar-Ilday et al., 2013).

Figure 15: This bar graph shows the correlation between gender and people aware that polyvinylsiloxane is used as die material for chair side work. The $\mathrm{X}$ axis shows the gender and the $\mathrm{Y}$ axis shows the responses. The green bar depicts the negative responses while the red shows the positive responses and blue bar shows people who are not sure about die material as polyvinyl siloxane. The chi square value is 0.4812 and the $P$ value is $0.786(>0.05)$. The $P$ value is not significant and no significant relationship is observed.

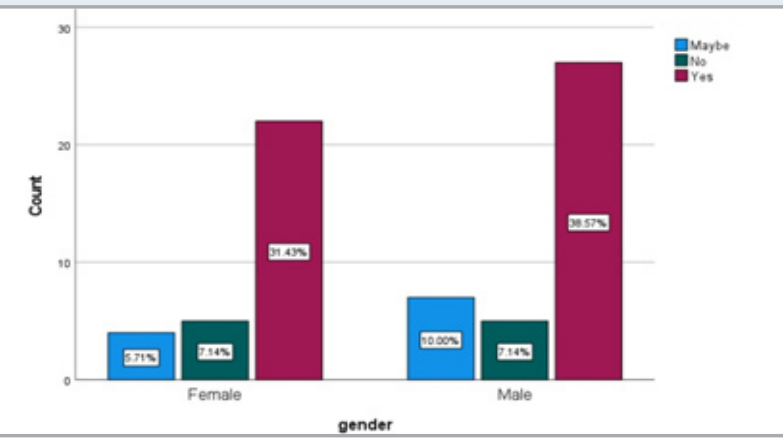

Figure 16: This bar graph shows the correlation between the gender and people aware of proper polishing protocol. The $\mathrm{X}$ axis shows the gender while the $\mathrm{Y}$ axis shows the responses. The green bar shows the negative responses and red bar shows the positive responses while the blue bar shows the people who are not sure of the proper polishing protocol to be followed for indirect composite. The chi square value is 1.6041 and the $P$ value is $0.448(>0.05)$. There is no significant $P$ value hence, no significant relationship is observed.

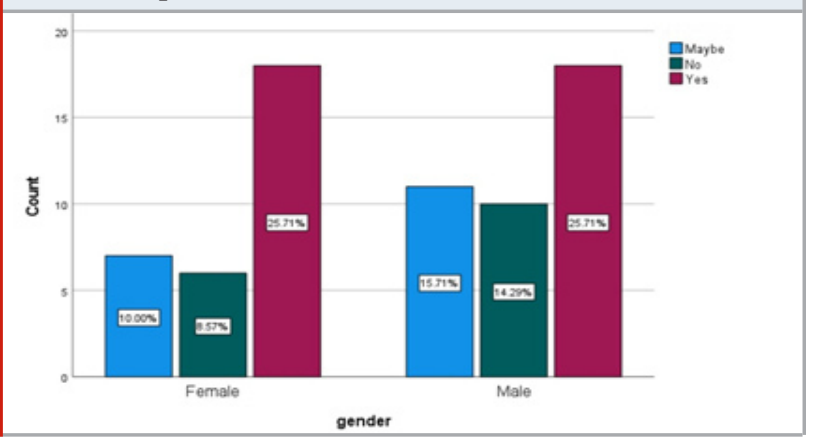

\section{CONCLUSION}

Aesthetics is playing an important role in modern dentistry and indirect composite is more aesthetic when compared to other materials. It is of absolute importance to have in-depth knowledge of indirect composite to make better use of them in clinical practice. From this survey, nearly half of the population only was aware of indirect composite which makes the survey even more important to help in spreading awareness. More seminar, conference, webinar, panel discussion, workshop is needed to improve the knowledge.

\section{ACKNOWLEDGEMENTS}

We thank Saveetha Dental College for providing us a platform and encouraging us to do research activities.

Conflict of Interest: None to declare

\section{REFERENCES}

Ajay, R. et al. (2017) 'Effect of Surface Modifications on the Retention of Cement-retained Implant Crowns under Fatigue Loads: An In vitro Study', Journal of pharmacy Et bioallied sciences, 9(Suppl 1), pp. S154-S160.

Alavi, A. A. and Kianimanesh, N. (2002) 'Microleakage of direct and indirect composite restorations with three dentin bonding agents', Operative dentistry, 27(1), pp. 19-24.

ALShetili, M. S. M. and Al-Omari, M. (2016) 'Color stability of nano-filled, micro-hybrid, and siloranebased dental composite resin materials', Saudi Journal of Oral Sciences. Medknow Publications and Media Pvt. Ltd., 3(1), p. 42.

Angerame, D. et al. (2012) 'The effects of scaling and root planing on the marginal gap and microleakage of indirect composite crowns prepared with different finish lines: an in vitro study', Operative dentistry, 37(6), pp. 650-659.

Araujo, F. S. et al. (2018) 'Effects of adhesive used as modeling liquid on the stability of the color and opacity of composites', Journal of esthetic and restorative dentistry: official publication of the American Academy of Esthetic Dentistry ... [et al.], 30(5), pp. 427-433.

Ariga, P. et al. (2018) 'Determination of Correlation of Width of Maxillary Anterior Teeth using Extraoral and Intraoral Factors in Indian Population: A Systematic Review', World Journal of Dentistry, pp. 68-75. doi: 10.5005/jp-journals-10015-1509.

Ashok, V. et al. (2014) 'Lip Bumper Prosthesis for an Acromegaly Patient: A Clinical Report', Journal of Indian Prosthodontic Society, 14(Suppl 1), pp. 279282.

Ashok, V. and Suvitha, S. (2016) 'Awareness of all ceramic restoration in rural population', Research Journal of Pharmacy and Technology. A \& V Publications, 9(10), pp. 1691-1693.

Azeem, R. A. and Sureshbabu, N. M. (2018) 'Clinical performance of direct versus indirect composite restorations in posterior teeth: A systematic review', Journal of conservative dentistry: JCD, 21(1), pp. 2-9. Bartlett, D. and Sundaram, G. (2006) 'An up to 3-year randomized clinical study comparing indirect and direct resin composites used to restore worn posterior teeth', The International journal of prosthodontics, 19(6), pp. 613-617. 
Basha, F. Y. S., Ganapathy, D. and Venugopalan, S. (2018) 'Oral Hygiene Status among Pregnant Women', Research Journal of Pharmacy and Technology, p. 3099. doi: 10.5958/0974-360x.2018.00569.3.

Borba, M., Della Bona, A. and Cecchetti, D. (2009) 'Flexural strength and hardness of direct and indirect composites', Brazilian oral research, 23(1), pp. 5-10.

Bortolotto, T. et al. (2013) 'Composite resin vs resin cement for luting of indirect restorations: comparison of solubility and shrinkage behavior', Dental materials journal, 32(5), pp. 834-838.

Duraisamy, R. et al. (2019) 'Compatibility of Nonoriginal Abutments With Implants: Evaluation of Microgap at the Implant-Abutment Interface, With Original and Nonoriginal Abutments', Implant dentistry, 28(3), p. 289.

Fuhrer, N. (1997) 'Restoring Posterior Teeth with a Novel Indirect Composite Resin System', Journal of Esthetic and Restorative Dentistry, pp. 124-130. doi: 10.1111/j.1708-8240.1997.tb00930.x.

Ganapathy, D. et al. (2016) 'Effect of Resin Bonded Luting Agents Influencing Marginal Discrepancy in All Ceramic Complete Veneer Crowns', Journal of clinical and diagnostic research: JCDR, 10(12), pp. ZC67-ZC70.

Ganapathy, D. M., Kannan, A. and Venugopalan, S. (2017) 'Effect of Coated Surfaces influencing Screw Loosening in Implants: A Systematic Review and Metaanalysis', World Journal of Dentistry, pp. 496-502. doi: 10.5005/jp-journals-10015-1493.

Jyothi, S. et al. (2017) 'Periodontal health status of three different groups wearing temporary partial denture', Research Journal of Pharmacy and Technology. A \& V Publications, 10(12), pp. 4339-4342.

Kannan, A. and Venugopalan, S. (2018) 'A systematic review on the effect of use of impregnated retraction cords on gingiva', Research Journal of Pharmacy and Technology. A \& V Publications, 11(5), pp. 21212126.

Kutuk, Z. B. et al. (2020) 'Influence of modeling agents on the surface properties of an esthetic nano-hybrid composite', Restorative dentistry \&t endodontics, 45(2), p. e13.

Leinfelder, K. F. (2005) 'Indirect posterior composite resins', The Compendium of continuing education in dentistry, 26(7), pp. 495-503; quiz 504, 527.

Mandikos, M. N. et al. (2001) 'A comparison of the wear resistance and hardness of indirect composite resins', The Journal of prosthetic dentistry, 85(4), pp. 386-395.

Nandini, S. (2010) 'Indirect resin composites', Journal of conservative dentistry: JCD, 13(4), pp. 184-194. Ozakar-Ilday, N. et al. (2013) 'Three-year clinical performance of two indirect composite inlays compared to direct composite restorations', Medicina oral, patologia oral y cirugia bucal, 18(3), pp. e521-8.
Ranganathan, H., Ganapathy, D. M. and Jain, A. R. (2017) 'Cervical and Incisal Marginal Discrepancy in Ceramic Laminate Veneering Materials: A SEM Analysis', Contemporary clinical dentistry, 8(2), pp. 272-278.

Reinhardt, J. W., Boyer, D. B. and Stephens, N. H. (1994) 'Effects of secondary curing on indirect posterior composite resins', Operative dentistry, 19(6), pp. 217220.

Rocca, G. T. et al. (2012) 'In vitro evaluation of marginal and internal adaptation after occlusal stressing of indirect class II composite restorations with different resinous bases and interface treatments. "Post-fatigue adaptation of indirect composite restorations"', Clinical Oral Investigations, pp. 1385-1393. doi: 10.1007/ s00784-011-0632-X.

Sedrez-Porto, J. A., Münchow, E. A. and Brondani, L. P. (2016) 'Effects of modeling liquid/resin and polishing on the color change of resin composite', Brazilian oral research. SciELO Brasil. Available at: https://www.scielo.br/scielo.php?pid=S180683242016000100275ctscript=sci_arttext.

Selvan, S. R. and Ganapathy, D. (2016) 'Efficacy of fifth generation cephalosporins against methicillin-resistant Staphylococcus aureus-A review', Research Journal of Pharmacy and Technology. A \& V Publications, 9(10), pp. 1815-1818.

Soares, C. J. et al. (2005) 'Marginal integrity and microleakage of direct and indirect composite inlays: SEM and stereomicroscopic evaluation', Brazilian oral research, 19(4), pp. 295-301.

Souza, R. 0. A. et al. (2010) 'Effect of different polymerization devices on the degree of conversion and the physical properties of an indirect resin composite', Acta odontologica latinoamericana: AOL, 23(2), pp. 129-135.

Subasree, S. and Murthykumar, K. (2016) 'Effect of Aloe Vera in Oral Health-A Review', Journal of pharmacy research. indianjournals.com. Available at: http://www. indianjournals.com/ijor.aspx?target=ijor:rjpt\&tvolume= 9tissue $=5$ Ctarticle $=028$.

Suzuki, S. et al. (2002) 'In vitro wear of indirect composite restoratives', The Journal of prosthetic dentistry, 88(4), pp. 431-436.

Venugopalan, S. et al. (2014) 'Magnetically retained silicone facial prosthesis', Nigerian journal of clinical practice, 17(2), pp. 260-264.

Vijayalakshmi, B. and Ganapathy, D. (2016) 'Medical management of cellulitis', Research Journal of Pharmacy and Technology. A \& V Publications, 9(11), pp. 2067-2070.

Zarrati, S. and Mahboub, F. (2010) 'Marginal adaptation of indirect composite, glass-ceramic inlays and direct composite: an in vitro evaluation', Journal of dentistry , 7(2), pp. 77-83. 